\title{
correspondence
}

\section{Nuclear decisions}

SIR,--In a recent article (22 February, page 594) Peter Taylor calls for changes in the way in which decisions are taken on nuclear energy matters. The article contains two straightforward issues and two more complex ones of interest to the Health and Safety Executive. Let me first dismiss the straightforward points.

The first is the reference to the alleged assumption that the issues are "primarily 'scientific' and 'technical', and thus ... the exclusive field of experts". I doubt if anyone really makes this assumption these days. It is certainly not a view held in the Health and Safety Executive.

The second issue relates to the Hinkley Point incident, which Peter Taylor has seriously misunderstood. The ministerial statement, to which he refers, makes it quite clear that the coolant involved was not the core coolant, which is carbon dioxide, but the sea water coolant for auxiliary equipment. Cooling was maintained by a jury-rigged system involving a fire pump. The reactor coolant was unaffected.

The most important of Peter Taylor's points relates to risk assessment. He casts quite legitimate doubts on the accuracy with which quantitative probability estimates can be made for various scales of accidents and their consequences. He goes on, however, to say that "probabilistic presentation obfuscates rather than illustrates the potential effects". On this I think he is wrong. The study of the range of accidents and consequences, including very serious ones, is helpful and is standard practice. The search for a worst case is less useful because of the difficulty of defining "worst". The worst case owes more to the imagination and inventiveness of its postulator than to reality. More seriously, the discussion of a worst case diverts attention and effort away from the more likely accidents. Moreover, a study of very serious accidents without reference to their likelihood does not provide any basis for decisions. Thus, for example, the worst possible accidents in many forms of transport, chemical processing and gas distribution would be unacceptable if they occurred frequently; it is the very low probability of these serious accidents that makes these industries acceptable in a society which relies heavily on the benefits they bring. It would be wrong to ban large passenger aircraft just because one might, one day, crash into a crowded stadium. It would be wrong precisely because the probability is very low, even though the consequences would be very severe.

Of course the probability and scale of accidents do not alone provide a definitive basis for decisions on, in particular, the licensing of nuclear installations. They do, however, provide an essential input.

The final point of importance relates to the supply of information. Peter Taylor writes of "a retreat into secrecy" but the alternative, moving towards greater openness, is not without difficulties. Much of the information in the detailed safety assessment of a plant is owned by the designer and is of real commercial válue to him. So long as we expect to have a commercial structure, nationally or internationally, to our nuclear industry this point will limit disclosure. I believe, and have said so in public, that there is too much use of the claim for commercial value and that we ought to move towards a more open situation. Bu this requires additional resources, both in the industry and in the Executive, and my hand is not strengthened when published information is misquoted and misused. The "selective use of the results of scientific research" is not confined to any one group.

\section{H. J. Dunster}

Health and Safety Executive, London.

SiR,--Peter Taylor (22 February, page 594) refers to the safety target which I proposed in 1967. He is right in quoting my view that the setting of a target in no way gives assurance that the target is or will be achieved.

Both the Flowers Report and the recent report of the Lewis Commission (USA) strongly support the use of fault trees and event trees for licensing purposes and to direct the research programme. Lewis also supports the Rasmussen methodology. Use of these techniques necessarily requires an adequate data base.

The Safety and Reliability Directorate (SRD), originally under my direction, have worked extremely hard during the last 13 years to collect relevant data and develop the highly disciplined and critical assessment techniques. These are now used in the nuclear industry and are being more widely used in the chemical and allied industries in association with over 60 agencies and major companies in over 16 countries.

I know that numerical assessment is not perfect and is not enough in isolation to determine design and operation but, rather than obfuscate, the need to obtain data and analyse quantitatively

wonderfully sharpens the mind and illuminates the problem, even if to show up its difficulties.

In my view the use of emotive words such as credible, incredible, maximum credible, did much to confuse safety issues in the first 10-15 years of reactor design.

Taylor asks that the worst condition should be stated. There is seldom a "worst". By assuming a combination of more and more unlikely events I am sure that I could develop a hypothetical situation to beat $\mathrm{Mr}$ Taylor, but of what value would this be?

When referring to the $A G R$ and the NRPB/NII study Mr Taylor quotes 100,000 and 600,000 casualties. The reader might reasonably believe this to be deaths, but paragraph 266 of the Flowers Report clearly states that the major effect would by thyroid damage. The number of deaths were estimated to be around about $300 / 400$ although this number could be an order of magnitude higher or lower.

As to the fast reactor, the Flower's Report (paragraph 304) states, "The consequences of such accidents would be so severe that the FBR could scarcely be contemplated on an extensive commercial basis unless it is established with a very high degree of confidence that reactivity accidents can be controlled so as to prevent gross fuel vaporisation." It is still my view and that of my colleagues that gross fuel vaporisation is highly improbable, and many international research programmes still continue to provide further evidence on this point

I support Mr Taylor's desire to ensure a highly critical approach on safety matters. We have done much to improve the standard of objective criticism in the UK, but I invite Mr Taylor to be equally concerned about the safety of man and the environment in all our industry.

F. R. FARMER (Safety Adviser to the UKAEA) United Kingdom

Atomic Energy Authority.

SIR,-Peter Taylor (22 February, page 595) states ". . . We were able to run NRPB calculations (which were for a notional site) for a specific locality (we chose Kalkar in West Germany). We discovered that NRPB had chosen not to present their own worst calculations-the results of one weather category which led to 600,000 casualties. Our site-specific study, having altered only the population data on the programme, produced over 900,000 casualties". Perhaps this concise account disguises the actual situation and I should like to reply in the absence abroad of Dr G. N. Kelly, the principal author.

When NRPB published its initial study of consequences of notional fast reactor accidents (Kelly, G. N., Jones, J. A. and Hunt, B. W., An estimate of the radiological consequences of notional accidental releases of radioactivity from a fast breeder reactor, NRPB-R53), it stated that "further analyses are being undertaken to assess the sensitivity of the results to variations of the more important parameters". At that stage no calculation of the type referred to by $\mathrm{Mr}$ Taylor had been done. In fact, the first sensitivity analysis has just been published (Kelly, G. N., Jones, J. A. and Simmonds, J. R., The influence of the physico-chemical form of the aerosol on the radiological consequences of notional accidental releases of radioactivity from a fast breeder reactor, NRPB-R73). Further studies are in hand which will include variation in meteorological conditions and population densities, from the likely parameters used in the initial study to the remote but nevertheless possible extremes. It is notable that the Political Ecology Research Group itself showed (RR-1, A study of consequences to the public of a severe accident at a commercial FBR located at Kalkar, West Germany) that the increased magnitude of the consequences in the worst conditions is broadly compensated for by the lower frequency of occurrence, giving comparable risks.

When NRPB has completed its investigations they will be published through HMSO.

National Radiological Protection Board. 